\title{
From the Editor of Sexuality and Disability: Knowledge is Based upon Diversity of Thought and Perspective
}

\author{
Sigmund Hough ${ }^{1}$ \\ Published online: 20 May 2019 \\ (c) Springer Science+Business Media, LLC, part of Springer Nature 2019
}

The journal of Sexuality and Disability continues to be a professional home and foundation for many, and a place of professional rejuvenation and exploration for many more. If you are new to the journal, we give to you a "BIG WELCOME" and invite you to participate as a reader, author, academician, clinician, educator, service provider, researcher, advocate, individual or individuals seeking information. Over decades of contribution to the literature on sexuality and disability, we have been a part of the growth and understanding. Now most importantly, we continue to be a part of the change in how we look and examine the topic, the need, and the response in terms of best practice- evidence based approaches. With the intelligence, experience, motivation and supportive commitment from our authors, readership, peer reviewers and editorial board, and resources with guidance from the Springer Staff, our journal's mission continues to be strong and meaningful. This international team effort continues as a strength in the field of sexuality and disability.

Knowledge is not static, but dynamic. Filters of knowledge come from within and outside the individual. Opportunity, access and choice are factors that shape our knowledge. Most important, knowledge is based upon diversity of thought and perspective. Since 1978, Sexuality and Disability continues to refine our knowledge to have impact on education, research and practice.

Sexuality and Disability makes available original impact articles addressing the mental health and medical aspects of sexuality in relation to rehabilitation, hospital, academic and community settings, publishing up-to-date articles, case studies, clinical practice reports, reviews, featured articles, historical articles, special grand rounds topics, brief research reports and survey data reports. Value benefit is provided to authors through worldwide electronic exposure and professional access, while readership gains from scholarly contributions to advance the field through research, evidence-based, best-practice and educational articles. Individual contributions from the local and international community delivers a wealth of information with broad perspective on the topic of sexuality and disability.

Thank you for joining our professional efforts.

Sigmund Hough

Sigmund_Hough@hms.harvard.edu

Beverly, USA 